\title{
Environmental Factors Affecting the Accumulation of Rosmarinic Acid in Spearmint (Mentha spicata L.) and Peppermint (Mentha piperita L.)
}

\author{
Ronald S. Fletcher, Tannis Slimmon, and Laima S. Kott ${ }^{*}$ \\ Department of Plant Agriculture, University of Guelph, Guelph, ON, N1G 2W1, Canada
}

\begin{abstract}
Four spearmint, and two peppermint clonal lines, selected for enhanced rosmarinic acid content $\left(50-120 \mathrm{mg} \mathrm{g}^{-1}\right.$ rosmarinic acid DW), where up to $80 \%$ of the antioxidant activity was correlated to rosmarinic acid content, were examined to determine the effects of environmental and physiological conditions on the accumulation of rosmarinic acid in leaf tissues. Exposure to a short photoperiod of 12 hours in comparison to 16 hours reduced rosmarinic acid accumulation in two mint lines, but no significant difference was found between photoperiods of 14 and 16 hours. The physiological age of the plant strongly influenced the accumulation of rosmarinic acid with the highest levels recorded in the vegetative state, and a significant reduction in the concentration of rosmarinic acid in the leaves in both the bud initiation and flowering stages in the mint lines. Cold stress, impacted over a six week period had no effect on rosmarinic acid production. A field study of the commercial chemotype 700B indicated that soil type plays an essential role in the accumulation of rosmarinic acid in the leaf tissue, probably due to retention of moisture which favours rosmarinic acid production. For producers and extractors, taking these factors into account would significantly increase rosmarinic acid accumulation in commercially high rosmarinic acid mint and increase the quality control of plant extracts for the natural products industry.
\end{abstract}

Keywords: Rosmarinic acid, spearmint, peppermint, environmental and physiological conditions.

\section{INTRODUCTION}

Mentha spicata L. (spearmint) and Mentha piperita L. (peppermint) are commonly produced as a crop for their essential oils for food products, cosmetics and pharmaceuticals. Peppermint and spearmint also produce rosmarinic acid (RA), a naturally occurring and potent polyphenolic antioxidant, which plays a role in modulating inflammatory diseases including allergies, asthma and atherosclerosis [1-3]. RA is generally found at the 2 to $4 \mathrm{mg}$ $\mathrm{g}^{-1}$ dry weight biomass level in mints, but chemotypes with higher levels can be found by selecting with abiotic or biotic selection agents [4]. The stability of enriched chemotypes becomes a significant factor in delivering a high quality product with increased nutraceutical value. Environmental factors such as photoperiod [5], water availability [6, 7], temperature [6], pest and disease incidence [8-10] are key to mint production due to the perennial nature of the crop. These factors have a direct impact on biochemical pathways, thus affecting the metabolism of secondary products. For example, spearmint plants enriched for RA exhibit a direct, negative correlation between the accumulation of RA and the antioxidant capacity spearmint extracts from plants grown at high temperatures [11]. Other researchers have found that cold temperatures can enhance the accumulation of RA in rosemary but is dependent on the chemotype [12]. This study examines the changes in RA accumulation in different chemotypes of mint leaf tissue due to environmental effects

*Address correspondence to this author at the Department of Plant Agriculture, University of Guelph, Guelph, ON, N1G 2W1, Canada; Tel: (519) 824-4120; Fax: (519) 763-8933; E-mail: 1kott@uoguelph.ca (photoperiod, cold stress, soil type, year to year differences) and the effect of physiological status of the plant in indoor tests or field trials.

\section{MATERIALS AND METHODS}

\section{Plant Material and Chemicals}

Spearmint seed (Mentha spicata L.) was sourced from Stokes Seeds Ltd., St. Catharines ON, Canada and peppermint seed (Mentha piperita L.) was purchased from Mountain Valley Seeds, Salt Lake City, UT, USA. Both spearmint and peppermint seed was previously mutated and selected for enhanced RA content using blockers of phenylalanine ammonia lyase [13]. Genetic integrity of these spearmints was maintained by clonal propagation and grown in a controlled indoor growth room environment as well as in a field nursery in 4-meter rows at the University of Guelph, Research Station (UGRS), Guelph ON, Canada. A number of different mint clones were variously used in this study, namely, 5 spearmint clones (700B, 1400A, EMS1B, SM1, SM2) and 2 peppermint clones (P10, P13)[13]. All standard phenolics and reagent chemicals were purchased from Sigma-Aldrich (Mississauga, ON, CA) unless otherwise stated.

\section{Analysis of RA and Phenolics}

For all field and indoor studies, RA levels were scored to identify optimum environmental conditions for maximum RA production. RA data was generated for each study separately, namely, the RA baseline for each clone, for the indoor photoperiod and cold stress study, and for the physiological stages, 2 year comparisons and 2 location field comparisons. 
Extracts for chemical and antioxidant analysis were prepared using approximately $5 \mathrm{mg}$ of dried ground leaf material and was extracted into $3 \mathrm{~mL}$ of $50 \%$ ethanol/water via microwave extraction ( 2 x 60 s, 200 watts). Extracts were cooled to room temperature then filtered through cotton plugged pipette tips to remove any particulates. Extracts were prepared daily to limit any potential oxidative degradation.

High performance liquid chromatography profiling of the spearmint and peppermint clones was completed by analyzing the remainder of the extracts previously used for the determination of total phenolics. Separation of phenolic compounds was achieved using a Gilson Unipoint analytical system (Gilson Corp, Middleton, WI, USA) accessorized with a $4.6 \times 250 \mathrm{~mm}$ C18 reverse phase column (Discovery column, Supelco, Bellefonte, PA, USA). Separation was achieved using a gradient solvent system comprised of $0.1 \%$ phosphoric acid/water (A) and acetonitrile (B) was used to separate the phenolics and flavonoids via a protocol developed in our lab: $0 \mathrm{~min}, 25 \% \mathrm{~B} ; 12 \mathrm{~min}, 45 \% \mathrm{~B} ; 15 \mathrm{~min}$, $95 \% \mathrm{~B} ; 18 \mathrm{~min}, 95 \%$ B for 5 minutes then re-equilibrated to

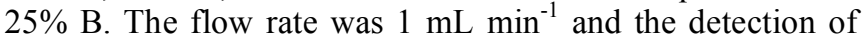
polyphenols was achieved by using a Gilson 118 UV/VIS detector set to $270 \mathrm{~nm}$. RA was identified and quantified by comparison to retention times and peak areas with an injected standard (triplicate injections).

\section{Antioxidant Capacity from Mint Extracts}

Nitrogen radical scavenging activity was measured by monitoring the reduction of the free nitrogen radical 2,2diphenyl-1-picrylhydrazyl (DPPH) in the presence of either the spearmint or peppermint extracts. Briefly, a DPPH solution $\left(1.0 \times 10^{-4} \mathrm{M}\right.$ in ethanol) was prepared fresh 24 hours prior to each experiment. Sample extracts $(5 \mu \mathrm{L})$ were added to the wells of a 96 well micro titer plate and the DPPH free radical solution $(245 \mu \mathrm{L})$ was added to mix with the sample aliquot and compared to a RA standard. After 30 minutes, total antioxidant capacity was determined by the observed diminution of absorbance at $515 \mathrm{~nm}$. The radical scavenging activity was expressed as a percent quench of the DPPH radical, calculated by [( $\mathrm{Abs} 0$ - Abs 30 minutes $) /$ Abs0] x 100. All determinations were completed in triplicate or quadruplicate with 2 independent extracts from each spearmint and peppermint clone (6-8 replicates) and then averaged. This data represented baseline data for the vegetative stage of the mint chemotypes.

\section{Indoor Studies}

\section{Photoperiod Effect on RA Accumulation}

Four clonal lines of spearmint and two clonal lines of peppermint were initially grown under normal growth room conditions $\left(16 \mathrm{~h}\right.$ day, $20 / 18^{\circ} \mathrm{C} \mathrm{d} / \mathrm{n}$, lighting from Sylvania 48" T8 fluorescent lamp type FO32/850/XP/ECO yielding $235 \mu \mathrm{mol} \mathrm{m}{ }^{-2} \mathrm{~s}^{-1}$ or $13.5 \mathrm{~mol} \mathrm{~m}$ day) in $10 \mathrm{~cm}$ pots for 4 weeks to an average height of $7.5 \mathrm{~cm}$ prior to exposure to different photoperiods. Five plants from each spearmint and peppermint clone were transferred to ConViron growth chambers set at either a 12-hour or 14 hour photoperiod $\left(20 / 18^{\circ} \mathrm{C} \mathrm{d} / \mathrm{n}\right)$, while five clones each were maintained as controls under normal growth room conditions (16 h day, $20 / 18^{\circ} \mathrm{C} \mathrm{d} / \mathrm{n}$ ). Plants were watered daily. One sprig from each of the five clones were harvested from day 0 control and subsequently harvested from each experimental and control plant every seven days for a period of 4 weeks. After the 4 weeks, clones from the 12 and 14-hour photoperiods were transferred back to the growth room and acclimatized for 1 week, then harvested once again at the end of the recovery period. Sprigs were dried at $35^{\circ} \mathrm{C}$ via air flow in paper bags for four days to prevent the degradation of RA and reduction of antioxidant capacity. In a previous study on the effects of heat drying of post-harvest spearmint, it was found that rapid drying with moderate heat most efficiently stabilized the RA in leaf tissues whereas high heat destroyed the RA [11].

\section{Effect of Physiological Plant Stages and RA Accumulation}

Mint plants were grown in a 16 hour day $\left(20 / 18^{\circ} \mathrm{C} \mathrm{d} / \mathrm{n}\right.$, lighting from Sylvania 48" T8 fluorescent lamp type FO32/850/XP/ECO yielding $235 \mu \mathrm{mol} \mathrm{m}^{-2} \mathrm{~s}^{-1}$ or $13.5 \mathrm{~mol} \mathrm{~m}^{-2}$ day) in $10 \mathrm{~cm}$ pots for six weeks and sampled from the vegetative stage, into pre-flower and in the flowering state for RA accumulation. Sprigs were dried and extracted as previously described.

\section{Cold Stress Effect on RA Accumulation}

Mint plants were grown under normal growth room conditions $\left(16 \mathrm{~h}\right.$ day, $20 / 18^{\circ} \mathrm{C} \mathrm{d} / \mathrm{n}$, lighting from Sylvania 48" T8 fluorescent lamp type FO32/850/XP/ECO yielding $235 \mu \mathrm{mol} \mathrm{m}{ }^{-2} \mathrm{~s}^{-1}$ or $13.5 \mathrm{~mol} \mathrm{~m}^{-2}$ day) in $10 \mathrm{~cm}$ pots for 4 weeks to an average height of $7.5 \mathrm{~cm}$ prior to exposure $4^{\circ} \mathrm{C}$, while control plants were maintained in the normal conditions. Sprigs were harvested weekly over a six week period, dried, processed and analyzed for RA content as described.

\section{Field Studies}

Spearmint clone 700B was established at UGRS, Guelph in a large $85 \times 41$ metre plot in heavy clay soil in June 2005 . In late 2006, RA level monitoring began on the biomass from the established field, and in 2007 full weekly monitoring was initiated from May to October. In 2007, several thousand plants were harvested from the Guelph site and transferred to Aylmer, ON Canada (approximately 150 $\mathrm{km} \mathrm{SW}$ ) to a sandy loam soil to establish a one hectare field of 700B. In 2008, monitoring of the RA levels of the Aylmer site was initiated for comparison of RA production values between the 2 Ontario sites. It was important to establish the effects of growing location, soil type and rate of establishment on RA production for any future commercial endeavors. The 700B spearmint clone field plot in Guelph provided the data for RA levels in comparisons between the two years 2007 vs 2008, and the two locations in Ontario (Guelph vs Alymer) in 2008.

\section{Statistical Analyses}

Regression analyses were performed to identify significant changes in RA content and total antioxidant capacity during the four-week period that the experimental plants were subjected to 12 and 14-hour photoperiods. For each clone the RA content and the antioxidant capacity were compared between weeks 1 to 4 of exposure to the specific photoperiod. Results of the analysis using the five control plants with a 16-hour photoperiod were then compared with 
the results from the five experimental plants for each clone. Results are reported as no difference, a significant increase, or a significant decrease in rosmarinic and total antioxidant capacity over the four-week period. Furthermore, the correlation between RA content and the antioxidant capacity was also performed for each of the 4 weeks with respect to photoperiodic exposure. All statistics were done using the program, Statistica (StatSoft, Release 5, Microsoft Corp., Redmond, WA, USA).

\section{RESULTS AND DISCUSSION}

\section{RA Baseline Levels and Antioxidant Capacity of Mint Clones}

Spearmint contains numerous polyphenols and flavonoids, each contributing to the antioxidant activity of an aqueous ethanol extract. The profiles of the mint extracts indicated that RA levels were between $61-91 \%$ of the total phenolic content, and dependent on chemotype, $51-82 \%$ of the antioxidant activity is explained by the RA content in the extract since the antioxidant activity correlated well with the HPLC phenolic profiles (Table 1).

Other phenolic acids identified in the profile were $p$ coumaric, caffeic and ferulic acids, found in very low quantities and most likely contributed only a small amount to the antioxidant capacity of the extract. RA clearly is the dominant phenolic acid in the HPLC profile and the major antioxidant of these enhanced mint extracts.

\section{Indoor Study: Photoperiod Effect on RA Accumulation}

Plants of 6 mint clones were exposed to three different photoperiods $(12,14,16 \mathrm{~h})$ to determine the effect of day length on RA accumulation in tissues. Most clones showed no significant differences with increased daylight hours (Table 2), however, two mint clones did show statistically significant increases between 12 and 16 hours of daylight (700B, SM2).

Table 1. Correlation between RA Content and Antioxidant Activity in the Mint Lines. 51-82\% of the Antioxidant Activity is Accounted for by the RA Content of the Mint Tissue

\begin{tabular}{|c|c|c|c|c|}
\hline \multirow{2}{*}{ Mint Line } & \multicolumn{4}{|c|}{ Statistical Analysis } \\
\cline { 2 - 5 } & $\mathbf{R}^{\mathbf{2}}$ & Intercept & Slope & $\mathbf{n}$ \\
\hline \hline 700B & 0.80 & 21.29 & 0.40 & 75 \\
\hline P10 & 0.79 & 20.59 & 0.36 & 75 \\
\hline P13 & 0.51 & 36.73 & 0.35 & 75 \\
\hline 1400A & 0.68 & 18.71 & 0.42 & 75 \\
\hline EMS1B & 0.82 & 23.54 & 0.36 & 75 \\
\hline SM1 & 0.77 & 30.50 & 0.32 & 74 \\
\hline SM2 & 0.78 & 21.99 & 0.52 & 65 \\
\hline
\end{tabular}

For the $700 \mathrm{~B}$ clone the increase was already statistically significant between 12 and 14 hours of daylight. Therefore, in general, the results suggest that a 14 hour day length is sufficient to reach maximum RA accumulation in these spearmint and peppermint clones. Therefore, to optimize RA accumulation in mint clones pre-selected for high commercial RA production, they should be cultivated in more temperate regions where growing season photoperiods exceed 14 hours. Since the summer solstice in mid June between $30^{\circ} \mathrm{N}$ and $60^{\circ} \mathrm{N}$ latitude provides $15-17$ hours of daylight, this latitudinal region would provide the optimal conditions for RA accumulation. Two drawbacks for not recommending growing these high RA clones in tropical regions for commercial production would be the shorter photoperiods and the excessive heat [11].

Table 2. Statistical Analysis of the Effect of Day-Length on the Accumulation of RA in High RA Mint Leaf Tissue. The Study was Done Over a Six Week Period with Samples Taken Weekly. A Total of Five Individual Plants were Sampled Per Line

\begin{tabular}{|c|c|c|c|}
\hline Line & $\begin{array}{c}\text { 12 Hours } \boldsymbol{v s} \\
\mathbf{1 4} \text { Hours }\end{array}$ & $\begin{array}{c}\mathbf{1 4} \text { Hours } \boldsymbol{v s} \\
\mathbf{1 6} \text { Hours }\end{array}$ & $\begin{array}{c}\mathbf{1 2} \text { Hours } \boldsymbol{v s} \\
\mathbf{1 6} \text { Hours }\end{array}$ \\
\hline \hline $700 \mathrm{~B}$ & SIG* & NS & SIG* \\
\hline P10 & NS & NS & NS \\
\hline P13 & NS & NS & NS \\
\hline 1400A & NS & NS & NS \\
\hline EMS1B & NS & NS & NS \\
\hline SM1 & NS & NS & NS \\
\hline SM2 & NS & NS & SIG** \\
\hline Significance $* \mathrm{p}<0.01,{ }^{* *} p<0.05$. & &
\end{tabular}

\section{Indoor Study: Cold Stress Effect on RA Accumulation}

Surprisingly, cold stress had no effect on the accumulation of RA in tissues. Normally, cold temperatures create oxidative stress in tissues wherein plants respond by an increase in the phenolic content to quench free radicals forming in the tissues. However, in this case, no statistically significant change in RA was observed in these mint clones over a 6 week, $4^{\circ} \mathrm{C}$ cold stress period (Fig. 1).

Therefore, RA seems to have no role in the cold stress response in these high RA-producing mint clones, and that RA levels are sufficiently high enough to accommodate the cold stress period.

\section{Indoor Study: Physiological Plant Stage and RA} Accumulation

Time of harvest in relation to the physiological stage of the plant is also an important factor in optimizing the yield of a particular product of plant origin. For example, spearmint and peppermint plants that are harvested just before flowering or in a pre-flowering state, yield the highest amount of essential oils in commercial production [14]. Several physiological plant stages were tested for optimal RA accumulation in this study and interestingly, the vegetative state accumulated the highest amount of RA in the plant tissues. As plants approached the pre-flowering stage levels of RA dropped considerably in most chemotypes except for two (Fig. 2). 


\section{EMS1B}

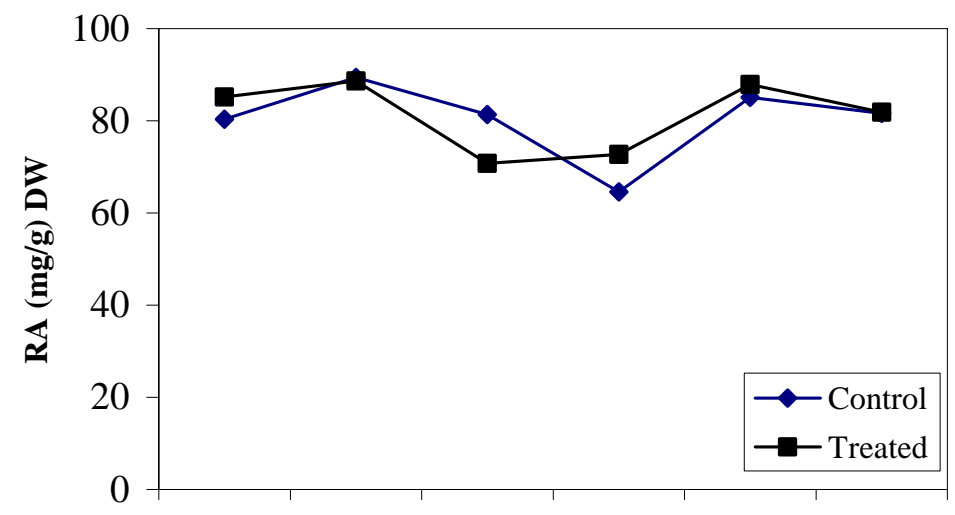

Week 1 Week 2 Week 3 Week 4 Week 5 Week 6

$1400 \mathrm{~A}$

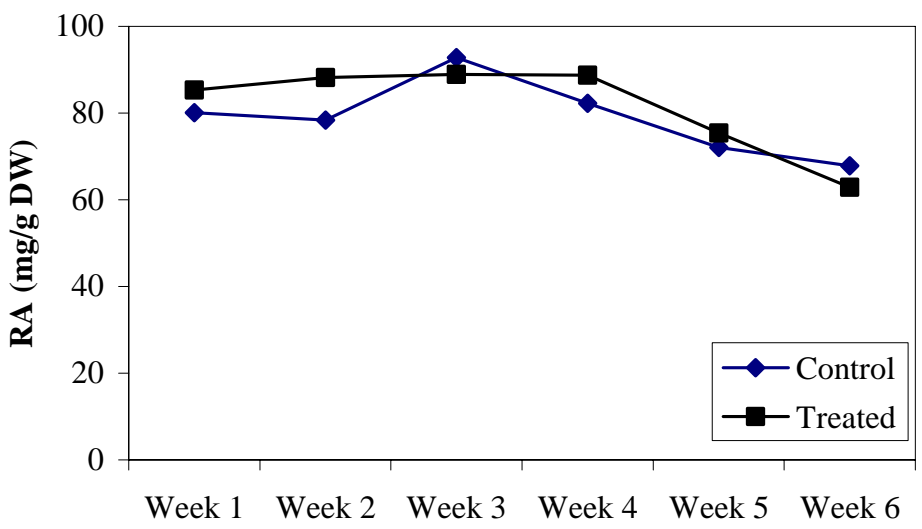

Fig. (1). Two examples of the effect of cold stress on RA levels in high RA-selected mints. During 6 weeks of cold stress at $4^{\circ} \mathrm{C}$, no significant difference was observed in the RA levels between the treated and the control plants maintained at $21^{\circ} \mathrm{C}$. The graphs are representative for all mint clones sampled in this study.

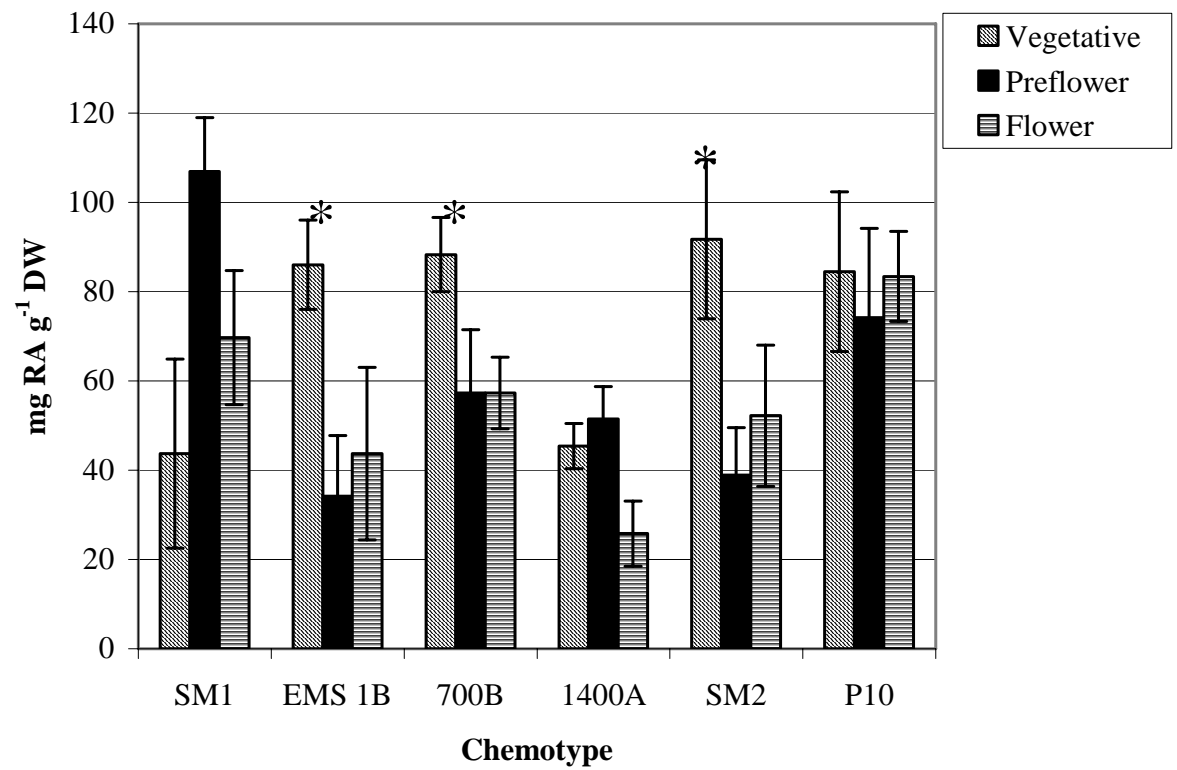

Fig. (2). Graphic representation of RA levels in leaf tissue in the vegetative, pre-flowering and flowering states of enhanced RA mint lines. Four replicates were sampled for each line as representation for each of the physiological states with error bars representing standard deviations. 
As the plants advanced to the flowering stage, levels of RA showed some recovery, however, the increase was not statistically significant compared to the pre-flowering stage. These observations are supported by similar field experiments performed by Papageorgiou and coworkers in rosemary where RA concentrations in tissues were higher before flowering $[15,16]$. Results indicate that as the physiological state moves towards reproduction, resources may be reallocated away from RA production to the reproductive phase. Phenolics are most likely drawn towards the production of lignin and suberin formation for stem strengthening for structural integrity and to flavonoid production for flowering.

\section{Field Study: Two Year Comparison in RA Accumulation at the Guelph Site}

The data from the Guelph site showed that in early spring the RA levels are very high throughout the month of June for both 2007 and 2008, sometimes peaking at above the level of $120 \mathrm{mg} \mathrm{g}^{-1}$ on a dry weight basis (Fig. 3). At this time the mint is in a leafy vegetative state and growing rapidly. Biomass is at a maximum at the end of June and beginning of July when plants are at a height of approximately 25 to 30 $\mathrm{cm}$ and also RA levels are high with normal levels of rainfall at this time of year.

Flowering begins in early to mid July and is correlated with the onset of RA decline (Fig. 3). Indoor experiments under controlled conditions have confirmed that as flowering occurs there is a rapid decrease in the RA levels in the leaves (Fig. 2). Once flowers are removed and vegetative growth resumes, RA levels begin to increase (data not shown). This was corroborated in the 2008 field season, where the levels of RA in late August returned to acceptable levels (>80 mg $\mathrm{g}^{-1}$ RA DW in Fig. 3).
The 2007 summer was exceptionally dry, and there was very little rain through the months of July and August as compared to the summer of 2008. Therefore, it appears that the drought forced a steady decline in RA levels during these months in 2007 reaching a low of $45 \mathrm{mg} \mathrm{g}^{-1} \mathrm{DW}$ by August $14^{\text {th }}$. Some recovery was made in late September when RA levels returned to the $70 \mathrm{mg} \mathrm{g}^{-1} \mathrm{DW}$ range (data not shown), however, the mint was in a slow state of re-growth during this period. In contrast, 2008 had ample moisture during July and August allowing the RA levels in the field to increase after flowering and a fresh field cut (Fig. 3).

\section{Field Study: RA Accumulation Comparison at 2 Sites in 2008}

A comparison of RA accumulation in the 700B clone at the Guelph and Aylmer sites was carried out during June, July and August of 2008 Harvest dates and drying methods were identical at both locations to reduce variables. Clearly, during June the Aylmer site never generated the high RA levels that were found during the same period at the Guelph site (50 to $73 \mathrm{mg} \mathrm{g}^{-1}$ vs 99 to $104 \mathrm{mg} \mathrm{g}^{-1}$ RA DW, respectively) (Fig. 4). However, a similar pattern emerged at both sites showing a simultaneous drop in RA levels with the emergence of the flowers near the end of June and the beginning of July. These results are similar to those observed by Papageorgiou and coworkers during harvests of rosemary in Greece, where RA content began to decline after the plant began to enter the flowering stage $[15,16]$. It is conceivable that this may be a common mechanism in the Lamiaceae, thus for commercial RA extraction purposes the vegetative state prior to flower bud formation and flowering becomes the crucial time for harvest.

The RA levels at the Aylmer site were consistently lower than at the Guelph site in 2008 , but by the end of July and

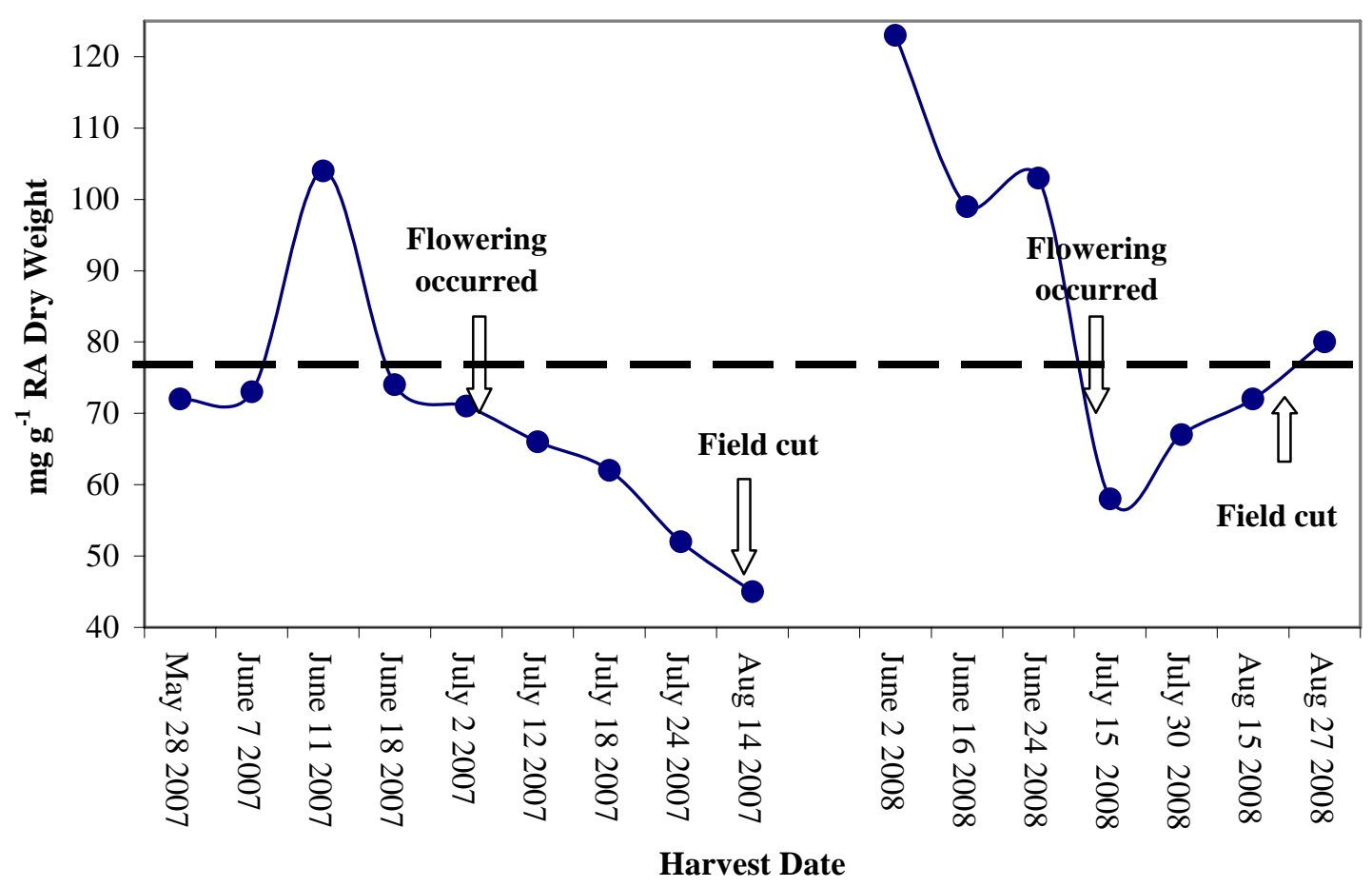

Fig. (3). Field RA levels in $\mathrm{mg} \mathrm{g}^{-1} \mathrm{DW}$ monitored over a two year period at the Guelph site. The dashed line at $78 \mathrm{mg} \mathrm{g}^{-1} \mathrm{RA}$ DW indicates commercial levels for harvest. 


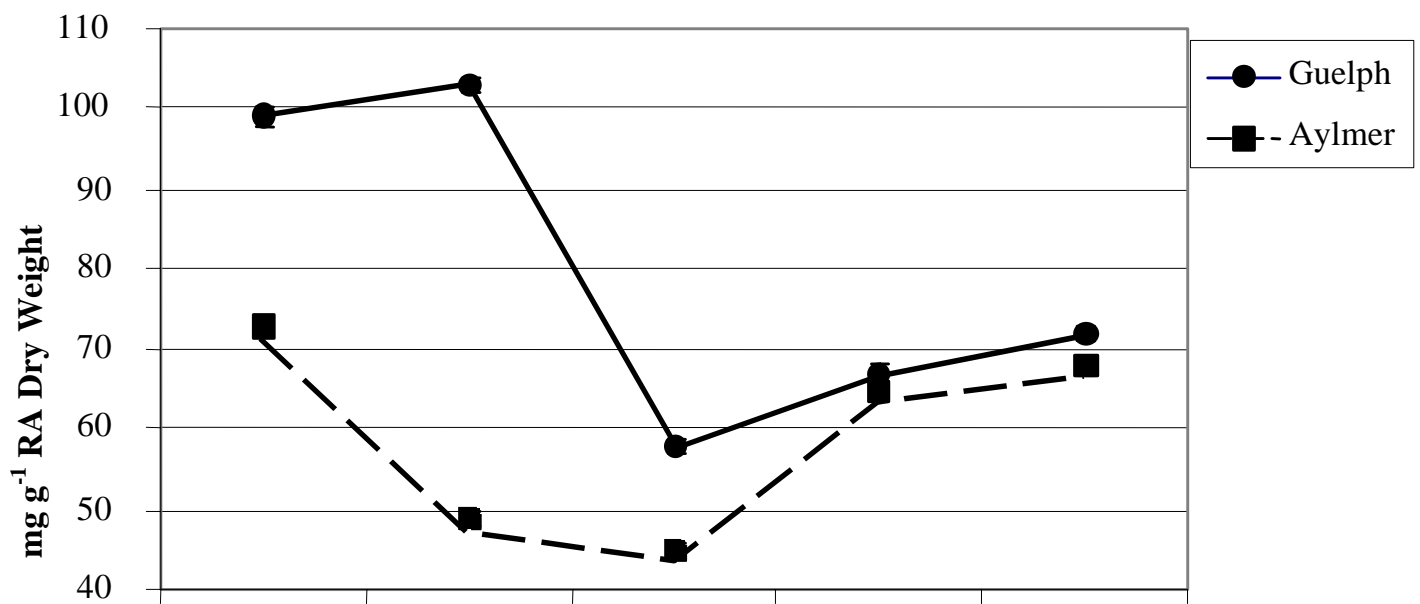

June 1608 June 2408 July 1508 July 3008 Aug 1508

Harvest Date 2008

Fig. (4). Possible effect of soil type on RA accumulation in mint tissues where the Guelph site is dominated by a heavy clay material and the Aylmer site is a sandy loam. RA determinations were performed by HPLC with a standard deviation of $0.1 \mathrm{mg} \mathrm{g}^{-1} \mathrm{DW}$.

through August the Aylmer site did approach the same RA level as the Guelph site, although this recovery was never close to optimal levels reached in June (Fig. 4). Preliminary data obtained in the latter half of 2007 also showed the same effect.

Soil analysis was performed at the Aylmer site to consider nutrient deficiencies as a possible cause of limited RA production. Adequate nitrogen and phosphorus levels were found, eliminating these variables. The major variable between these locations is the soil type. The Guelph site has rich heavy clay which retains moisture well whereas the Aylmer site has a sandy loam which drains moisture quickly.

Although clone 700B grows well at both sites, clearly soil quality must be taken into account if commercial production of RA is considered. Other soil characteristics may also play a part and remains to be investigated.

\section{CONCLUSIONS}

Flowering plays a crucial role in the reduction of RA levels in spearmint and peppermint. Therefore, it is critical that plants are harvested during the vegetative phase, prior to flowering to maximize the RA content of the leaves of mint. A first harvest in June would allow enough time for ample biomass re-growth, given sufficient moisture, to become available for a second harvest in late August. The shortening day length during this regrowth period, ensures that new flower buds are not initiated, the crop remains in the vegetative stage and therefore RA and biomass can return to high commercial levels for a second harvest during a single growing season.

Furthermore, day length appears not to play an essential role in the production and accumulation of RA in mint tissues. However, to maximize RA accumulation in these pre-selected high RA-producing mint clones, it is crucial that they are grown in areas with long days exceeding 14 hours.
Optimal latitudes in the northern hemisphere would lie between 30 and 60 degrees north.

Soil type may play a role in the levels of accumulated RA in the mint. Although light, sandy soils are excellent in generating ample mint biomass, the low water holding capacity of sand is not conducive to production of high levels of RA in leaf tissues as compared to a clay soil base.

\section{REFERENCES}

[1] Makino T, Furata Y, Wakushima H, Fuji H, Saito K, Kano Y. Antiallergic effect of Perilla frutescens and its active constituents. Phytother Res 2003; 17: 240-3.

[2] Inoue K, Takano H, Shiga A, et al. Effects of volatile constituents of a rosemary extract on allergic airway inflammation related to house dust mite allergen in mice. Int J Mol Med 2005; 16:315-9.

[3] Shixian Q, Da Y, Kakuda Y, et al. Synergistic anti-oxidative effects of lycopene with other bioactive compounds. Food Rev Int 2005; 21:295-311.

[4] Al-Amier H, Mansour B, Toaima N, Korus R, Shetty K. Screening of high biomass and phenolic producing clonal lines of Spearmint in tissue culture using Pseudomonas and azetidine-2 carboxylate. Food Biotech 1999; 13: 227-53.

[5] Voirin B, Brun N, Bayet C. Effects of day-length on the monoterpene composition of leaves of Mentha x piperita. Phytochemistry 1990; 29: 749-55.

[6] Clark R, Menary R. Environmental effects on the peppermint (Mentha piperita L.). Effect of day length, photon flux density, night and day temperature on yield and composition of peppermint oil. Aust J Plant Physiol 1980; 7: 685-92.

[7] Muniram T, Singh S, Ram D, Singh D. The effect of irrigation on the yield and oil quality of mints. Int J Trop Agric 1992; 10: 21925 .

[8] Morris M, Berry R, Croft B. Fall flaming effects on densities, distributions, and dispersal of Tetranychus urticae and Neoseiulus fallacies (Acari: Tetranychidae, Phytoseiidae) on peppermint. Environ Entomol 2000; 29: 95-100.

[9] Edwards J, Bienvenu F. Evaluation of selected fungicides to control mint rust on Scotch spearmint. Crop Prot 2000; 19: 195-9.

[10] Johnson D, Cummings T. Evaluation of mint mutants, hybrids, and fertile clones for resistance to Verticillium dahliae. Plant Dis 2000; 84: 235-8.

[11] Fletcher R, Slimmon T, McAuley C, Kott L. Heat stress reduces the accumulation of rosmarinic acid and the total antioxidant 
capacity in spearmint (Mentha spicata L). J Sci Food Agric 2005; 85: 2429-36.

[12] Luis J, Martin R, Frias I, Valdes F. Enhanced carnosic acid levels in two rosemary accessions exposed to cold stress conditions. J Agric Food Chem 2007; 55: 8062-6.

[13] Kott L, Fletcher R. Inventors. Production of rosmarinic acid from spearmint and uses thereof. US patent pending PCT/IB2008/0009 782008 Jan.

[14] Weller S, Green R, Janssen C, Whitford F. Mint production and pest management in Indiana. Available from: http://www.btny.pur due.edu/Pubs/PPP/PPP-103.pdf (2000).
[15]

Papageorgiou V, Mallouchos A, Komaitis M. Investigation of the antioxidant behavior of air- and freeze-dried aromatic plant materials in relation to their phenolic content and vegetative cycle. J Agric Food Chem 2008; 56: 5743-52.

[16] Papageorgiou V, Gardeli C, Mallouchos A, Papaioannou M, Komaitis M. Variation of the chemical profile and antioxidant behavior of Rosmarinus officinalis L. and Salvia fruticosa miller grown in Greece. J Agric Food Chem 2008; 56: 7254-64.

Received: April 17, 2009

Revised: May 22, 2009

Accepted: May 27, 2009

(C) Fletcher et al.; Licensee Bentham Open.

This is an open access article licensed under the terms of the Creative Commons Attribution Non-Commercial License (http: //creativecommons.org/licenses/by$\mathrm{nc} / 3.0 /$ ) which permits unrestricted, non-commercial use, distribution and reproduction in any medium, provided the work is properly cited. 